\title{
CREB1 and Smad3 mediate TGF-ß3-induced Smad7 expression in rat hepatic stellate cells
}

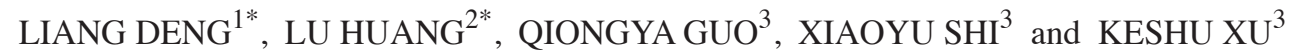 \\ ${ }^{1}$ Department of Gastroenterology, The First Affiliated Hospital of Chongqing Medical University, Chongqing 400016; \\ ${ }^{2}$ Department of Immunology, Children's Hospital of Chongqing Medical University, Chongqing 400014; \\ ${ }^{3}$ Department of Gastroenterology, Union Hospital, Tongji Medical College, Huazhong University \\ of Science and Technology, Wuhan, Hubei 430022, P.R. China
}

Received February 10, 2016; Accepted February 1, 2017

DOI: $10.3892 / \mathrm{mmr} .2017 .7654$

\begin{abstract}
Transforming growth factor (TGF)- $\beta 3$ has previously been reported to antagonize hepatic fibrosis in vivo and in vitro. The present study aimed to investigate the mechanism underlying the involvement of TGF- $\beta 3$ in hepatic fibrosis. Short hairpin (sh)RNA-cAMP-responsive element binding protein (CREB) 1 and small interfering (si)RNA-Smad3 were utilized to silence the expression of CREB1 and Smad3 in hepatic stellate cells (HSCs), whereas the vector pRSV-CREB1 was used to induce CREB1 overexpression in HSCs. Cells were treated with or without exogenous TGF- $\beta 3$ or TGF- $\beta 1$, and mRNA and protein expression levels were assessed using reverse transcription-quantitative polymerase chain reaction and western blot analysis. Untreated cells served as the control group. Exogenous TGF- $\beta 3$ increased Smad7 mRNA and protein expression levels in rat HSCs, and CREB1 and Smad3 appeared to be implicated in the mechanism of Smad7. CREB1 knockdown inhibited the TGF- $\beta 3$-induced upregulation of Smad7, whereas its overexpression potentiated the Smad7 upregulation in HSCs; conversely, CREB1 manipulations had no effect on Smad7 expression under basal conditions. In addition, TGF- $\beta 3$-induced Smad7 upregulation was blocked when the activity of p38, a kinase upstream of CREB1, was inhibited. Furthermore, silencing Smad3 resulted in decreased Smad7
\end{abstract}

Correspondence to: Professor Keshu Xu, Department of Gastroenterology, Union Hospital, Tongji Medical College, Huazhong University of Science and Technology, 1277 Jiefang Road, Wuhan, Hubei 430022, P.R. China

E-mail:xuzou@medmail.com.cn

*Contributed equally

Abbreviations: BMP, bone morphogenetic protein; CRE, cAMP responsive element; CREB1, cAMP responsive element binding protein 1; ERK, extracellular signal-regulated kinase; HSC, hepatic stellate cell; JNK, c-Jun N-terminal kinase; TGF- $\beta$, transforming growth factor- $\beta$; PKA, protein kinase A

Key words: liver fibrosis, CREB1, TGF- $\beta 3$, Smad7, Smad3, HSCs expression under basal conditions and in TGF- $\beta 3$-stimulated cells. Notably, Smad7 expression appeared to also be induced by exogenous TGF- $\beta 1$, independent of CREB1. The present study demonstrated that TGF- $\beta 3$ increased Smad7 expression in HSCs, whereas CREB1 and Smad3 appeared to participate in the mechanism of induction. Smad3 is the key regulator whereas CREB-1 acts as a co-regulator. These results suggested that this mechanism may underlie the antagonizing effects of TGF- $\beta 3$ on hepatic fibrosis.

\section{Introduction}

Hepatic fibrosis is a common response to chronic hepatic injury of varying etiology, and is associated with the aberrant deposition of extracellular matrix components in the liver. An event of critical importance during its progression is the activation of hepatic stellate cells (HSCs) $(1,2)$. Transforming growth factor (TGF)- $\beta 1$ is a major fibrogenic factor in the liver, which has been reported to contribute to the activation and proliferation of HSCs (2). Preventing the activation of HSCs or inhibiting the activity of TGF- $\beta 1$ have been demonstrated to reverse the progression of fibrosis (3).

The TGF- $\beta$ superfamily comprises three different isoforms in mammals, namely TGF- $\beta 1$, TGF- $\beta 2$ and TGF- $\beta 3$, each participating in distinct biological functions (4). TGF- $\beta 1$ has traditionally been considered a key fibrogenic and proliferative stimulus in HSCs, whereas TGF- $\beta 3$ has an antagonistic effect on the actions of TGF- $\beta 1$. Recombinant TGF- $\beta 3$ has been reported to inhibit the mRNA and protein expression of TGF- $\beta 1$, suppress collagen synthesis and upregulate the expression of matrix metalloproteinase- 9 in HSCs. Furthermore, the expression of type I collagen was revealed to be decreased in pcDNA3.1(+)-TGF- $\beta 3$ and pcDNA3.1(+)-TGF- $\beta 1$ co-transfected HSCs compared with pcDNA3.1(+)-TGF- $\beta 1$ transfected HSCs, a finding that may indicate that TGF- $\beta 3$ inhibited TGF- $\beta 1$ signaling. In addition, recombinant adeno-associated virus $2-\mathrm{TGF}-\beta 3$ treatment was reported to reduce the histopathological damage associated with liver fibrosis in rats treated with carbon tetrachloride in vivo (5-7). However, the mechanism underlying the antagonistic effects of TGF- $\beta 3$ on TGF- $\beta 1$-induced liver fibrosis has yet to be elucidated. 
Activation of the TGF- $\beta 1 /$ Smad signaling pathway is implicated in the response to hepatic fibrosis. In this pathway, TGF- $\beta 1$ binds to the TGF- $\beta$ receptor (R) II, triggering the phosphorylation of TGF- $\beta$ RI, which results in the activation of downstream receptor-regulated Smad proteins (R-Smads), including Smad2 and Smad3. Phosphorylated R-Smads oligomerize with Smad4 to form a transcriptional complex, which translocates to the nucleus to activate the transcription of target genes. Inhibitory Smads (I-Smads), including Smad6 and Smad7, are negative regulators of this pathway (8). Therefore, it may be hypothesized that TGF- $\beta 3$ can inhibit hepatic fibrosis via regulating the TGF- $\beta 1 /$ Smad signaling pathway in HSCs.

Our previous study demonstrated that cAMP-responsive element binding protein (CREB) 1 is a critical transcription factor implicated in TGF- $\beta 3$ autoregulation in HSCs (9). CREB1 is expressed in numerous cell types and acts as a transcription factor to regulate promoter activity via binding to cAMP-responsive elements (CREs). Previous studies have suggested that CREB1 may be involved in fibrogenic processes in various tissues, including the heart and lungs; however, the exact role of CREB1 in fibrosis, as well as its implication in hepatic fibrosis, have yet to be elucidated (10-12). Notably, CREB1 has been reported to cooperate with bone morphogenetic protein (BMP)-stimulated Smad signaling to enhance activation of the Smad6 promoter in chondrocytes (13). Therefore, it may be hypothesized that the regulatory effects of CREB1 on I-Smads contribute to the inhibitory action of TGF- $\beta 3$ on fibrogenic processes in HSCs.

The present study demonstrated that TGF- $\beta 3$ induced Smad7 expression in HSCs. CREB1 and Smad3 are required for this induction, with Smad3 acting as the key regulator and CREB1 acting as a co-regulator. These results suggested that this mechanism may underlie the antagonizing effects of TGF- $\beta 3$ on hepatic fibrosis.

\section{Materials and methods}

Materials. The phenotypically activated rat HSC-T6 cell line was obtained from the Hepatopathy Institute of Shanghai University of Traditional Chinese Medicine (Shanghai, China). TGF- $\beta 3$ and TGF- $\beta 1$ were purchased from PeproTech, Inc. (Rocky Hill, NJ, USA) and their purity was $>98 \%$, as assessed via SDS-PAGE. pGenesil-1.1-short hairpin (sh)RNA-CREB1 (3'-CGGUGUCUAACGGUGUAAU-5') was purchased from Wuhan GeneSil Biotechnology Co., Ltd. (Wuhan, China). pRSV-CREB1 expression vector (9) was obtained from Dr Michael Greenberg (Department of Neurobiology, Harvard Medical School, Boston, MA, USA). Small interfering (si)RNA-Smad3 was purchased from Qiagen China Co., Ltd. (SI00255983; Shanghai, China). SP600125, a c-Jun N-terminal kinase (JNK) inhibitor; SB203580, a p38 inhibitor; PD98059, a mitogen-activated protein kinase kinase (MEK) inhibitor; and H89, a protein kinase A (PKA) inhibitor, were purchased from Santa Cruz Biotechnology, Inc. (Dallas, TX, USA). TRIzol ${ }^{\circledR}$ reagent, primers and SYBR Green I were purchased from Invitrogen (Thermo Fisher Scientific, Inc., Waltham, MA, USA).

Cell culture. HSCs were cultured in Dulbecco's modified Eagle's medium (DMEM) supplemented with $10 \%$ fetal bovine serum (both from Thermo Fisher Scientific, Inc.) and maintained at $37^{\circ} \mathrm{C}$ in a $5 \% \mathrm{CO}_{2}$ atmosphere. All experiments were conducted when cells were at the exponential phase of growth. Cells were seeded into $25 \mathrm{~cm}^{2}$ plastic culture flasks or 6 -well plates until $70-80 \%$ confluent, and treated with exogenous TGF- $\beta 3$ or TGF- $\beta 1(10 \mathrm{ng} / \mathrm{ml})$ at $37^{\circ} \mathrm{C}$ for various durations. Cells that did not receive TGF- $\beta 3$ or TGF- $\beta 1$ served as the control group. HSCs were cultured in 6-well plates and treated with the JNK inhibitor SP600125 $(20 \mu \mathrm{M})$, the p38 inhibitor SB203580 $(20 \mu \mathrm{M})$, the ERK inhibitor PD98059 $(20 \mu \mathrm{M})$ or the PKA inhibitor H89 $(5 \mu \mathrm{M})$ for $30 \mathrm{~min}$, then stimulated with exogenous TGF- $\beta 3$ for an additional $2 \mathrm{~h}$ at $37^{\circ} \mathrm{C}$. In all experiments, control cells received a PBS vehicle treatment. Total RNA was extracted from cells belonging to all treatment groups for reverse transcription-quantitative polymerase chain reaction (RT-qPCR).

Transient transfection. siRNA-Smad3 was utilized to silence Smad3 expression in HSCs, pGenesil-1.1-shRNA-CREB1 was used to silence CREB1 expression via RNA interference, and pRSV-CREB1 expression vector was used to induce CREB1 expression. HSCs were seeded in 6-well plates and grown until 80-90\% confluent, then transiently transfected with siRNA-Smad3, pGenesil-1.1-shRNA-CREB1 or pRSV-CREB1, or AllStars Negative Control siRNA (Qiagen China Co.,Ltd.) or pGenesil-1.1-shRNA-KB ( $2 \mu \mathrm{g} /$ well; Wuhan GeneSil Biotechnology Co., Ltd.), using Lipofectamine ${ }^{\mathrm{TM}} 2000$ (Invitrogen; Thermo Fisher Scientific, Inc.) as the delivery agent. Each well contained $5 \mu$ l Lipofectamine 2000, $250 \mu 1$ Opti-MEM $^{\circledR}$ I Reduced Serum Medium (Gibco; Thermo Fisher Scientific, Inc.) and $2 \mathrm{ml} \mathrm{DMEM}$. A total of $5 \mathrm{~h}$ post-transfection, the culture medium was replaced with fresh DMEM and cells were incubated for an additional $17 \mathrm{~h}$ at $37^{\circ} \mathrm{C}$. Subsequently, $10 \mathrm{ng} / \mathrm{ml}$ exogenous TGF- $\beta 3 / \mathrm{TGF}-\beta 1$ was added to each well and HSCs were incubated for $2 \mathrm{~h}$ at $37^{\circ} \mathrm{C}$. Total RNA was extracted from cells belonging to all treatment groups and CREB1, Smad3 and Smad7 mRNA expression levels were assessed using RT-qPCR.

$R T-q P C R$. Total RNA was extracted from HSCs, which were treated as aforementioned, using TRIzol ${ }^{\circledR}$ reagent, according to the manufacturer's protocol. Total RNA was reverse transcribed into cDNA using a PrimeScript RT reagent kit with gDNA Eraser (Takara Biotechnology, Co., Ltd., Dalian, China). The residual genomic DNA was cleared by incubating at $42^{\circ} \mathrm{C}$ for 2 min with the gDNA Eraser enzyme. The pretreated total RNA was mixed with the buffer containing Oligo dT Primer and RT Enzyme, and was subsequently reverse transcribed into cDNA. qPCR was performed using SYBR Premix Ex Taq II (Tli RNaseH Plus; Takara Biotechnology, Co., Ltd.). Rat specific forward and reverse primer sequences (Table I) were designed using the Primer Premier software version 5.0 (PREMIER Biosoft, Palo Alto, CA, USA). The total PCR reaction volume of each sample was $20 \mu \mathrm{l}$, containing $1.6 \mu \mathrm{l}$ of each specific primer $(10 \mu \mathrm{M}), 10 \mu \mathrm{l} 2 \mathrm{X}$ SYBR Premix Ex Taq II reaction mix and $0.8 \mu 1$ of Rox Reference Dye (50x). The final cDNA concentration in each PCR reaction was $<100 \mathrm{ng}$. Amplification was performed using the ABI StepOne system (Applied Biosystems; Thermo Fisher Scientific, Inc.), under the following conditions: 1 cycle at $95^{\circ} \mathrm{C}$ for $10 \mathrm{~min}$, followed by 
Table I. Primer sequences used for reverse transcription-quantitative polymerase chain reaction.

\begin{tabular}{|c|c|c|c|}
\hline Name & Chain & Sequence & Gene ID \\
\hline \multirow[t]{2}{*}{ TGF- $\beta$ RI } & $\mathrm{F}$ & 5'-CACCGCGTACCAAATGAAGA-3' & NM_012775.2 \\
\hline & $\mathrm{R}$ & 5'-TGGTGCCCTCTGAAATGAAAG-3' & \\
\hline \multirow[t]{2}{*}{ TGF- $\beta$ RII } & $\mathrm{F}$ & 5'-GACAACTGCGCCATCATCCT-3' & NM_031132.3 \\
\hline & $\mathrm{R}$ & 5'-ATGTTGTTGGCGCACGTAGA-3' & \\
\hline \multirow[t]{2}{*}{ Smad3 } & $\mathrm{F}$ & 5'-GGGCCTGCTGTCCAATGT-3' & NM_013095.3 \\
\hline & $\mathrm{R}$ & 5'-AATGTGCCGCCTTGTAAGCT-3' & \\
\hline \multirow[t]{2}{*}{ Smad4 } & $\mathrm{F}$ & 5'-CCCGAGACAGAGCATCAAAGA-3' & NM_019275.2 \\
\hline & $\mathrm{R}$ & 5'-GAGCTCGGTGGAGGTGAATC-3' & \\
\hline \multirow[t]{2}{*}{ Smad6 } & $\mathrm{F}$ & 5'-CCACTGGATCTGTCCGATTCTAC-3' & NM_001109002.2 \\
\hline & $\mathrm{R}$ & 5'-GAGCAGTGATGAGGGAGTTGGT-3' & \\
\hline \multirow[t]{2}{*}{ Smad7 } & $\mathrm{F}$ & 5'-TGGATGGCGTGTGGGTTTA-3' & NM_030858.1 \\
\hline & $\mathrm{R}$ & 5'-TGGCGGACTTGATGAAGATG-3' & \\
\hline \multirow[t]{2}{*}{ Smurf1 } & $\mathrm{F}$ & 5'-CTGAAGGCTACGAGCAAAGGA-3' & NM_001109598.1 \\
\hline & $\mathrm{R}$ & 5'-CAGTCTGCGTGTGCAAAAAGTAA-3' & \\
\hline \multirow[t]{2}{*}{ Smurf2 } & $\mathrm{F}$ & 5'-GCCCACGGCTCTTTACCATA-3' & NM_025481.2 \\
\hline & $\mathrm{R}$ & 5'-GGGCTTTTGGCAGGTTGTT-3' & \\
\hline \multirow[t]{2}{*}{ GAPDH } & $\mathrm{F}$ & 5'-GTATGACTCTACCCACGGCAAGT-3' & NM_017008.4 \\
\hline & $\mathrm{R}$ & 5'-TTCCCGTTGATGACCAGCTT-3' & \\
\hline
\end{tabular}

TGF, transforming growth factor; R, receptor; Smurf, Smad specific E3 ubiquitin protein ligase.

40 cycles at $95^{\circ} \mathrm{C}$ for $5 \mathrm{sec}$, and at $60^{\circ} \mathrm{C}$ for $60 \mathrm{sec}$. Experiments were performed in triplicate. The relative expression levels of each gene were normalized to GAPDH and were calculated using the $2^{-\triangle \Delta \mathrm{Cq}}$ method (14).

Western blot analysis. Total protein (30-60 $\mu \mathrm{g}$ ) was extracted as previously described (9). Proteins were quantified using a bicinchoninic acid assay. Equal amounts (20-40 $\mu \mathrm{g})$ of extracted protein samples were separated by $12 \%$ SDS-PAGE and subsequently transferred to nitrocellulose membranes. The membranes were blocked with $5 \%$ non-fat milk for $1 \mathrm{~h}$ and incubated with anti-Smad7 (1:1,000; MAB2029; R\&D Systems, Inc., Minneapolis, MN, USA), anti-CREB1 (1:2,000, cat no. 9197), anti-phosphorylated (p)-CREB1 (1:1,000; cat no. 9198), anti-Smad3 (1:2,000; cat no. 9523) (all from CST Biological Reagents Co., Ltd., Shanghai, China) or anti-GAPDH (1:5,000; cat no. 2118; Cell Signaling Technology, Inc., Danvers, MA, USA) primary antibodies overnight at $4^{\circ} \mathrm{C}$. Membranes were then incubated with horseradish peroxidase-conjugated goat anti-rabbit secondary antibody (1:10,000; cat no. sc-2004; Santa Cruz Biotechnology, Inc.) for $2 \mathrm{~h}$ at room temperature. The protein bands were visualized using an enhanced chemiluminescence detection kit (Thermo Fisher Scientific, Inc.).

Statistical analysis. Statistical analysis was performed using SPSS software version 13.0 (SPSS, Inc., Chicago, IL, USA). Data are expressed as the mean \pm standard deviation. Statistical differences between groups were assessed using a t-test or a Mann-Whitney U test. When multiple groups were compared, one-way analysis of variance followed by Tukey's post hoc test was performed. $\mathrm{P}<0.05$ was considered to indicate a statistically significant difference.

\section{Results}

TGF- $\beta 3$ increases Smad7 expression in HSCs. To determine the mechanism underlying the implication of TGF- $\beta 3$ in hepatic fibrosis, the proteins participating in the TGF- $\beta 1 / \mathrm{Smad}$ signaling pathway were investigated in HSCs treated with or without exogenous TGF- $\beta 3$. TGF- $\beta 3$ significantly increased the mRNA expression levels of Smad6 and Smad7 in HSCs (Fig. 1A), by 1.5-fold and 3.6-fold, respectively $(\mathrm{P}<0.01)$. Conversely, TGF- $\beta 3$ had no effect on the mRNA levels of Smad3, Smad4, TGF- $\beta$ RI, TGF- $\beta$ RII, Smad specific E3 ubiquitin protein ligase (Smurf) 1 and Smurf2 (P>0.05). $\mathrm{Smad} 7$ is a prominent I-Smad in the TGF- $\beta 1 / \mathrm{Smad}$ signaling pathway, and its mRNA levels appeared higher compared with Smad6; therefore, the mRNA and protein expression levels of TGF- $\beta 3$-induced Smad7 were examined in HSCs treated with exogenous TGF- $\beta 3$ at various time-points. TGF- $\beta 3$ appeared to rapidly increase Smad7 mRNA levels (Fig. 1B and C), which peaked within $1 \mathrm{~h}$ following stimulation (4.1-fold higher compared with control). Induction of Smad7 protein expression appeared to decrease within $2 \mathrm{~h}$ following stimulation. The present results indicated that TGF- $\beta 3$ increased Smad7 expression in HSCs.

CREB1 is involved in TGF- $\beta 3$-induced Smad7 expression. Since the transcription factor CREB1 is a downstream target in the TGF- $\beta 3$ signaling pathway, its involvement in TGF- $\beta 3$-induced Smad7 expression was investigated. shRNA-CREB1 and 
A
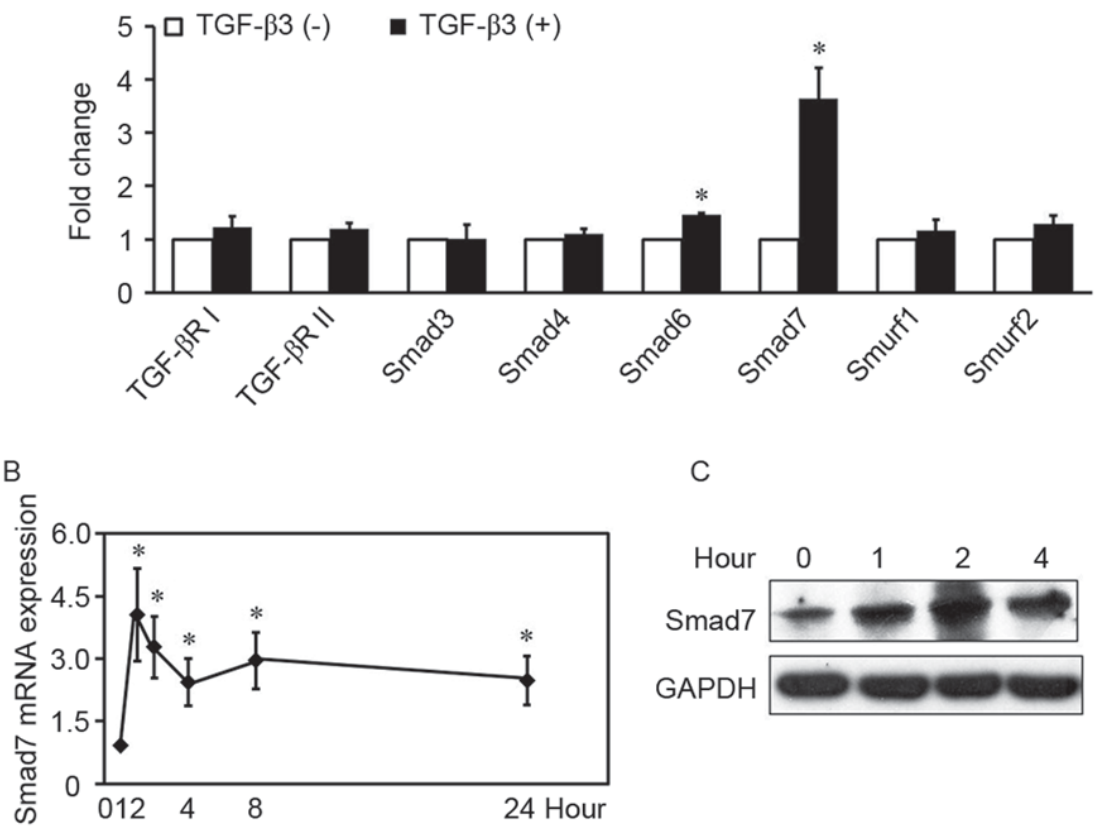

C

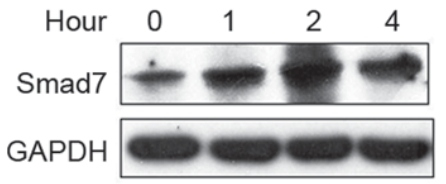

Figure 1. TGF- $\beta 3$ increases Smad7 expression in HSCs. (A) HSCs were treated with or without exogenous TGF- $\beta 3$ (10 ng/ml) for $2 \mathrm{~h}$, total RNA was extracted and TGF- $\beta$ RI, TGF- $\beta$ RII, Smad3, Smad4, Smad6, Smad7, Smurf1 and Smurf2 mRNA expression levels were detected by RT-qPCR. The expression of each gene in the control group is defined as $1(\mathrm{n}=5)$. (B) RT-qPCR analysis of Smad7 mRNA expression levels in HSCs treated with exogenous TGF- $\beta 3$ (10 ng/ml) at various time-points. Control is defined as $1(\mathrm{n}=6)$. Data are expressed as the mean \pm standard deviation. (C) Western blot analysis of Smad7 protein expression levels in HSCs treated with exogenous TGF- $\beta 3(10 \mathrm{ng} / \mathrm{ml})$ at various time-points. Three independent experiments were performed and a representative blot is presented. " $\mathrm{P}<0.01$, compared with control under basal unstimulated conditions. TGF, transforming growth factor; HSC, hepatic stellate cell; R, receptor; RT-qPCR, reverse transcription-quantitative polymerase chain reaction; Smurf, Smad specific E3 ubiquitin protein ligase.
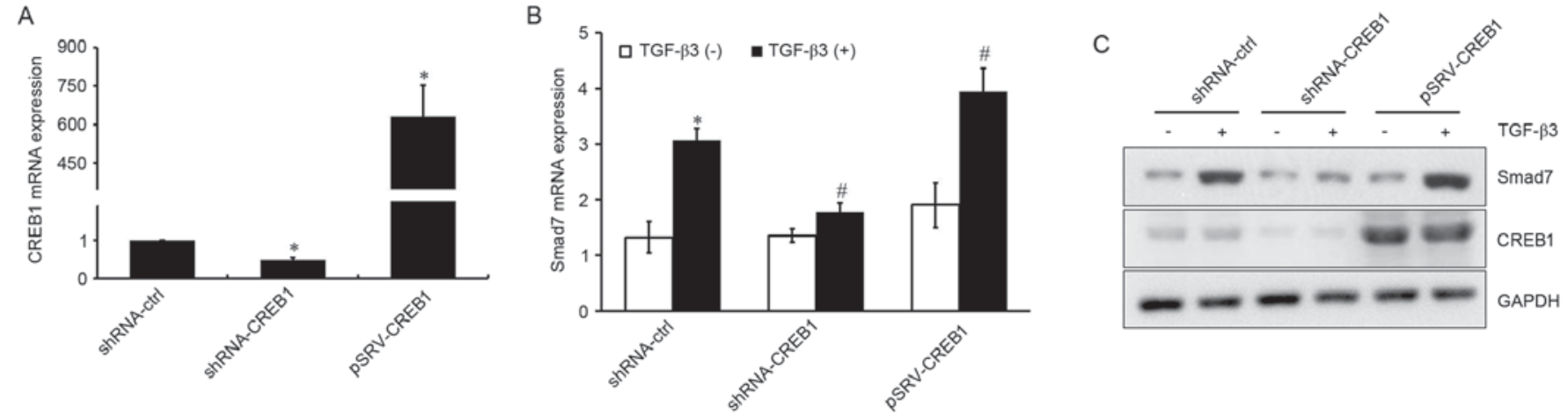

Figure 2. CREB1 is involved in TGF- $\beta 3$-induced Smad7 expression. (A and B) HSCs were transiently transfected with pGenesil-1.1-shRNA-control, pGenesil-1.1-shRNA-CREB1 or pRSV-CREB1 expression vector for $5 \mathrm{~h}$, incubated in media for $17 \mathrm{~h}$, and subsequently treated with or without exogenous TGF- $\beta 3$ $(10 \mathrm{ng} / \mathrm{ml})$ for $2 \mathrm{~h}$. Reverse transcription-quantitative polymerase chain reaction was performed to examine the mRNA expression levels of CREB1 and Smad7. Data are expressed as the mean \pm standard deviation. ${ }^{*} \mathrm{P}<0.05$ compared to control under basal unstimulated conditions; ${ }^{*} \mathrm{P}<0.05$ compared with cells transfected with control vector and treated with exogenous TGF- $\beta 3(n=5)$. (C) Western blot analysis of Smad7 and CREB1 protein expression levels in HSCs treated with exogenous TGF- $\beta 3(10 \mathrm{ng} / \mathrm{ml})$ for $2 \mathrm{~h}$. Three independent experiments were performed, and a representative blot is presented. CREB, cAMP responsive element binding protein; TGF, transforming growth factor; HSC, hepatic stellate cell; sh, short hairpin.

pRSV-CREB1 were used to silence or overexpress CREB1, respectively, in HSCs treated with or without exogenous TGF- $\beta 3$, and mRNA and protein expression levels of Smad7 were assessed using RT-qPCR and western blot analysis. As presented in Fig. 2A, CREB1 expression was significantly suppressed in shRNA-CREB1-transfected HSCs compared with in control cells $(\mathrm{P}<0.05)$, whereas it was upregulated in cells transfected with pRSV-CREB1 compared with in control cells $(\mathrm{P}<0.05)$. CREB1 downregulation was revealed to significantly inhibit TGF- $\beta 3$-induced Smad7 expression $(\mathrm{P}<0.05)$, whereas its overexpression enhanced the TGF- $\beta 3$-induced Smad7 upregulation ( $\mathrm{P}<0.05$; Fig. $2 \mathrm{~B}$ andC). However, CREB1 inhibition or overexpression had no effect on Smad7 expression under basal, unstimulated conditions $(P>0.05)$. These results suggested that CREB1 may be implicated in TGF- $\beta 3$-induced Smad7 expression, but may not be required for Smad7 expression when TGF- $\beta 3$ stimulation is absent.

TGF- $\beta 3$ activates CREB1 via p38 to induce Smad7. Mitogen-activated protein kinases (MAPKs) and PKA are 
A

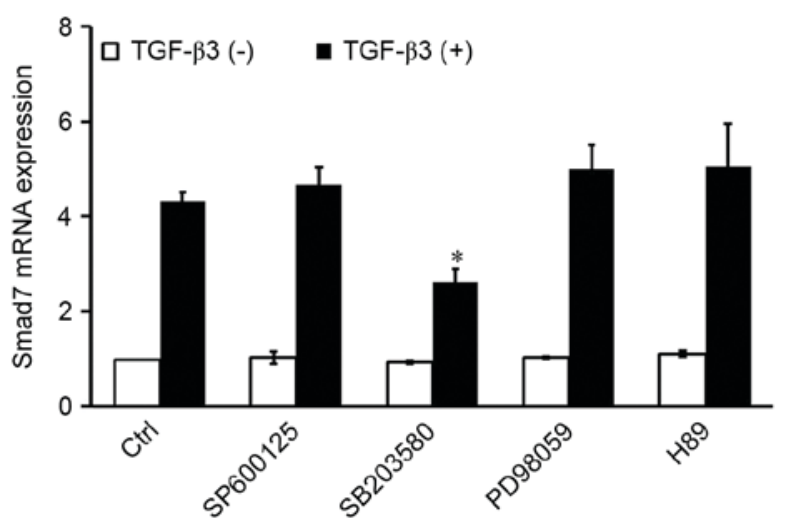

B

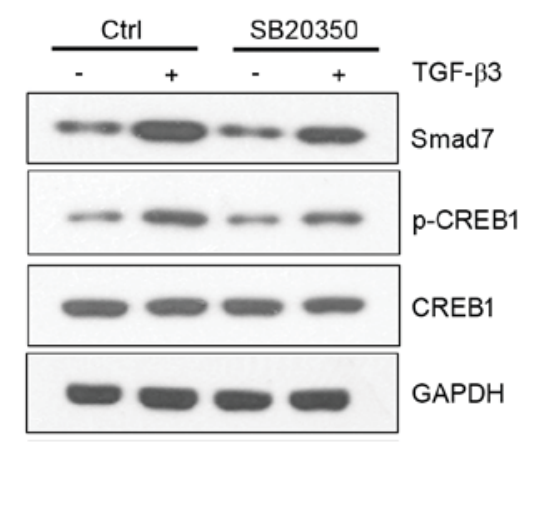

Figure 3. TGF- $\beta 3$ activates CREB1 via p38 to induce Smad7 expression. (A) HSCs were treated with the c-Jun N-terminal kinase inhibitor SP600125 (20 $\mu$ M), the p38 inhibitor SB203580 $(20 \mu \mathrm{M})$, the mitogen-activated protein kinase kinase inhibitor PD98059 $(20 \mu \mathrm{M})$, or the protein kinase A inhibitor H89 $(5 \mu \mathrm{M})$ for $30 \mathrm{~min}$, then treated with or without exogenous TGF- $\beta 3(10 \mathrm{ng} / \mathrm{ml})$ for $2 \mathrm{~h}$. Smad7 mRNA expression levels were assessed using reverse transcription-quantitative polymerase chain reaction. Control is defined as $1(\mathrm{n}=6)$. Data are expressed as the mean \pm standard deviation. " $\mathrm{P}<0.05$ compared to cells treated with exogenous TGF- 33 in the control group. (B) HSCs were treated with the p38 inhibitor SB203580 (20 $\mu \mathrm{M})$ for 30 min and then with or without exogenous TGF- $\beta 3$ (10 ng/ml) for $2 \mathrm{~h}$. Protein expression levels of CREB1, p-CREB1 and Smad7 were assessed using western blot analysis. Three independent experiments were performed and a representative blot is presented. TGF, transforming growth factor; CREB, cAMP responsive element binding protein; HSC, hepatic stellate cell; p-, phosphorylated.

kinases that translocate to the nucleus, where they phosphorylate CREB1 and facilitate its binding to the consensus CRE DNA site (15-17). To investigate whether JNK, ERK, p38 or PKA were implicated in CREB1 activation resulting in TGF- $\beta 3$-induced Smad7 expression, the following inhibitors were used: SP600125, a selective JNK inhibitor; SB203580, a selective p38 inhibitor; PD98059, a selective MEK inhibitor; and H89, a selective PKA inhibitor. The inhibitors had no effect on Smad7 expression under basal conditions. SB203580 significantly inhibited the TGF- $\beta 3$-induced Smad7 expression $(\mathrm{P}<0.05)$; however, the other inhibitors produced no effect (Fig. 3A). In addition, western blot analysis of protein expression levels revealed that SB203580 reduced p-CREB1 levels, and inhibited the TGF- $\beta 3$-induced Smad7 upregulation (Fig. 3B). These results suggested that TGF- $\beta 3$ may activate CREB1 through the p38 signaling pathway, resulting in potentiated Smad7 expression in HSCs.

Smad3 is required for TGF- $\beta 3$-induced Smad7 expression. The results of the present study indicated that CREB1 may not be required for Smad7 expression in the absence of TGF- $\beta 3$ stimulation, suggesting that other transcription factors are implicated in TGF- $\beta 3$-induced Smad7 expression. It has previously been reported that the Smad7 promoter contains a Smad binding element (SBE), and Smad3 has been demonstrated to induce its activity via binding to SBE in HEK293 cells (18). To investigate the role Smad3 serves in TGF- $\beta 3$-induced Smad7 expression in HSCs, siRNA was used to silence the Smad3 gene. The inhibitory efficiency of siRNA-Smad3 was $\sim 50 \%$ (Fig. 4A). Silencing the expression of Smad3 resulted in a marked reduction in the mRNA and protein expression levels of Smad7 under basal conditions and following TGF- $\beta 3$ stimulation ( $\mathrm{P}<0.05$; Fig. $4 \mathrm{~B}$ and $\mathrm{C})$. These results suggested that $\mathrm{Smad} 3$ may be implicated in the TGF- 33 -induced Smad7 expression in HSCs.

CREB1 has no effect on TGF- $\beta 1$-induced Smad7 expression in HSCs. It has previously been reported that Smad3 is an important downstream factor of TGF- $\beta 1$ (8). To investigate whether TGF- $\beta 1$ may also be able to induce Smad7 expression in HSCs, HSCs were cultured with or without exogenous TGF- $\beta 1$. Exogenous TGF- $\beta 1$ was revealed to induce Smad7 expression in HSCs $(\mathrm{P}<0.05$; Fig. 5A). Furthermore, HSCs were transfected with shRNA-CREB-1 or pRSV-CREB1 expression vector, and subsequently treated with or without exogenous TGF- $\beta 1$, in order to investigate the role of CREB1 in TGF- $\beta 1$-induced Smad7 expression. Notably, the inhibition or overexpression of CREB1 exerted no influence on TGF- $\beta 1$-induced Smad7 expression (Fig. 5).

\section{Discussion}

Smad6 and Smad7 belong to the I-Smad family, whose members have been reported to participate in the regulation of the signal transduction pathways of TGF- $\beta$ cytokines (19). It has previously been demonstrated that Smad7 inhibited TGF- $\beta$ Rand Activin receptor-mediated signaling pathways, whereas Smad6 has been reported to inhibit BMP signaling $(20,21)$. Smad7 is able to antagonize TGF- $\beta$ signaling through various mechanisms. It has been revealed that Smad7 interacted with TGF- $\beta$ RII to inhibit the phosphorylation of R-Smads and the subsequent formation of hetero-complexes between R-Smads and Smad4 (22). Smad7 has also been revealed to mediate the degradation of the activated type I receptor ALK5/T $\beta R I$ via recruiting HECT-type E3 ubiquitin ligases, such as Smurf1 and Smurf2 (23). Furthermore, Smad7 is able to bind the MH2 DNA domain and disrupt the formation of functional Smad-DNA complexes (24). TGF- $\beta 1$ serves a key role in fibrogenic processes in various tissues, including skin, liver, kidney, eye and lung, via inducing the Smad3-dependent transcription of fibrillar collagen types. Increased TGF- $\beta 1$ and decreased Smad7 expression is often observed in fibrotic tissues, whereas Smad7 overexpression is able to inhibit fibrotic responses in various tissues via antagonizing the TGF- $\beta 1 / \mathrm{Smad} 3$ signaling pathway (25-27). 
A

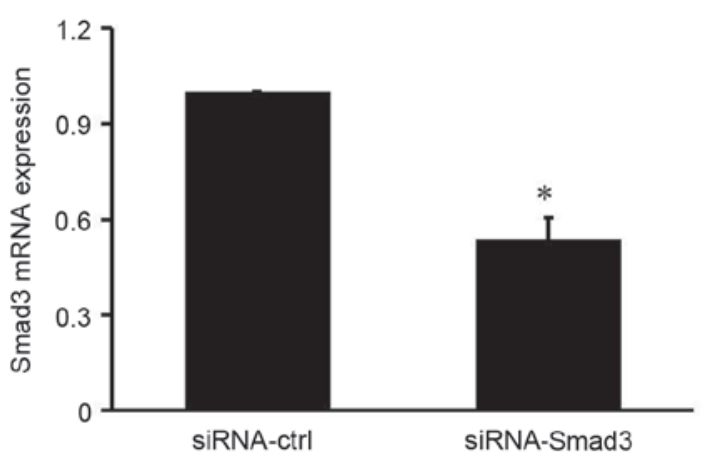

B

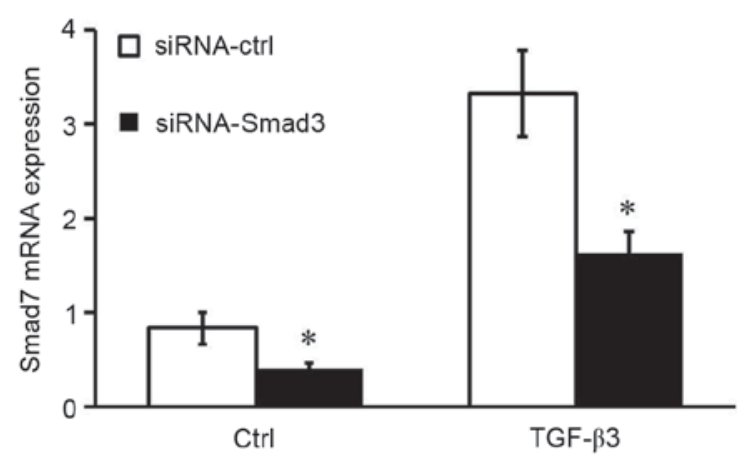

C

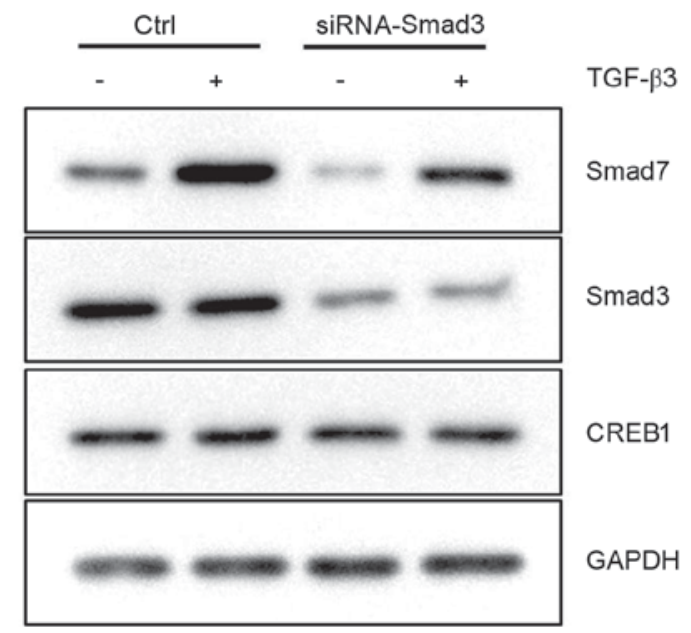

Figure 4. Smad3 is required for TGF- $\beta 3$-induced Smad7 expression. (A and B) HSCs were transiently transfected with siRNA-control or siRNA-Smad 3 for $5 \mathrm{~h}$, incubated in media for $17 \mathrm{~h}$, and subsequently treated with or without exogenous TGF- $\beta 3(10 \mathrm{ng} / \mathrm{ml})$ for $2 \mathrm{~h}$. Reverse transcription-quantitative polymerase chain reaction was used to examine the mRNA expression levels of $\operatorname{Smad} 3$ and $\operatorname{Smad} 7(n=6)$. Data are expressed as the mean \pm standard deviation. " $\mathrm{P}<0.05$ compared to control under basal unstimulated conditions. (C) HSCs were treated as aforementioned and the protein expression levels of CREB1, Smad3 and Smad7 were assessed using western blot analysis. Three independent experiments were performed and representative blot is presented. TGF, transforming growth factor; HSC, hepatic stellate cell; si, small interfering; CREB, cAMP responsive element binding protein.

It has previously been reported that TGF- $\beta 1$ and TGF- $\beta 3$ serve opposite roles in liver fibrosis (1-7). Although TGF- $\beta 1$ has been demonstrated to regulate the expression of Smad7, the role of TGF- $\beta 3$ has yet to be elucidated. In the present study, exogenous TGF- $\beta 1$ and TGF- $\beta 3$ were revealed to increase the expression of Smad7 in HSCs; however,
A

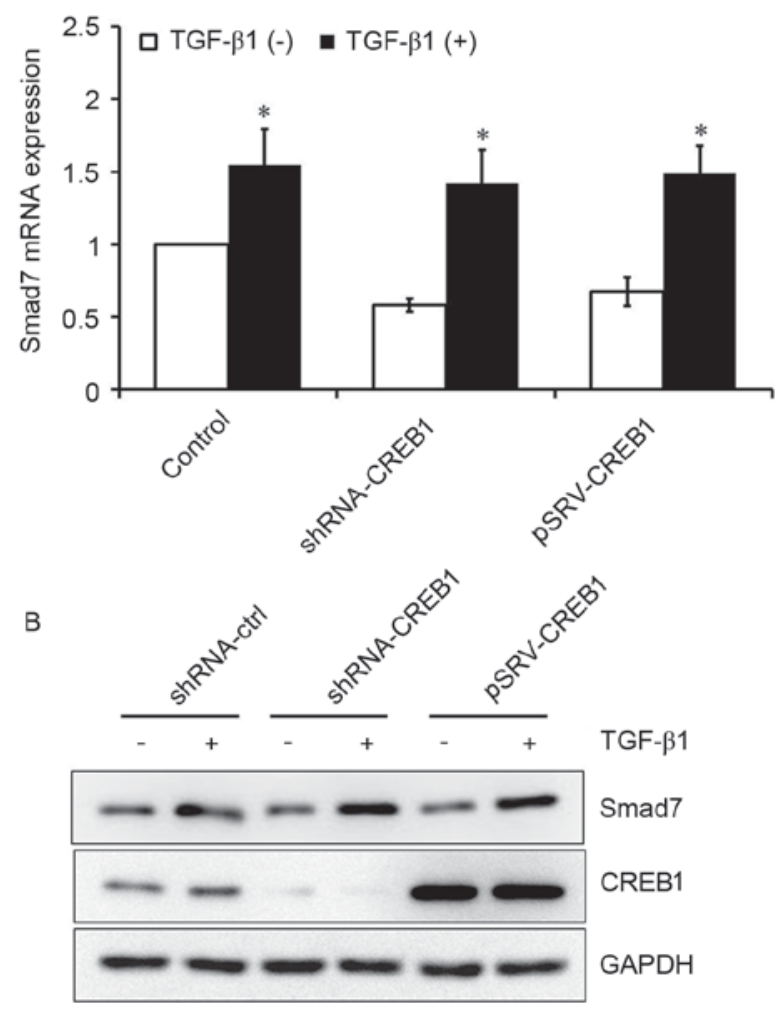

Figure 5. CREB1 exerts no effect on TGF- $\beta 1$-induced Smad7 expression in HSCs. (A) HSCs were transiently transfected with pGenesil-1.1-shRNA-control, pGenesil-1.1-shRNA-CREB1 or pRSV-CREB1 expression vector for $5 \mathrm{~h}$, incubated in media for $17 \mathrm{~h}$, and subsequently treated with or without exogenous TGF- $\beta 1(10 \mathrm{ng} / \mathrm{ml})$ for $2 \mathrm{~h}$. Reverse transcription-quantitative polymerase chain reaction was performed to examine Smad7 mRNA expression levels $(n=3)$. Data are expressed as the mean \pm standard deviation. ${ }^{*} \mathrm{P}<0.05$ compared to control under basal unstimulated conditions. (B) Western blot analysis was used to assess the protein expression levels of Smad7 and CREB1 in HSCs treated with exogenous TGF- $\beta 1(10 \mathrm{ng} / \mathrm{ml})$ for $2 \mathrm{~h}$. Three independent experiments were performed and a representative blot is presented. TGF, transforming growth factor; HSC, hepatic stellate cell; sh, short hairpin; CREB, cAMP responsive element binding protein.

TGF- $\beta 3$-mediated induction of Smad7 appeared more potent than the TGF- $\beta 1$-mediated induction, suggesting that different signaling pathways may be involved in these processes.

To explore the mechanism underlying TGF- $\beta 3$-induced Smad7 expression, the implication of CREB1 in this pathway was investigated. CREB1 is a key downstream transcription factor in the TGF- $\beta 3$ autoregulation signaling pathway (9), which has been reported to participate in the development of fibrosis $(10,11)$. Notably, the inhibition or overexpression of CREB1 produced no effect on Smad7 expression under basal conditions in HSCs that did not receive treatment, thus indicating that CREB1 may not be required for the physiological expression of Smad7. Conversely, the inhibition of CREB1 in vitro significantly decreased the TGF- $\beta 3$-induced Smad7 expression, whereas CREB1 overexpression enhanced the Smad7-stimulating effect of exogenous TGF- $\beta 3$ application. These results suggested that CREB1 may be implicated in TGF- $\beta 3$-induced Smad7 expression, where it acts as a co-regulator. In addition, p38 was revealed to be a key kinase upstream of CREB1 that is activated in response to TGF- $\beta 3$ stimulation. 
CREB1 did not appear to exert an effect on TGF- $\beta 1$-induced Smad7 expression.

As a member of the TGF- $\beta$ superfamily, TGF- $\beta 3$ can also activate the downstream factor Smad3, through phosphorylation of the TGF- $\beta \mathrm{R}$ (28). In order to characterize the role of Smad3 in TGF- 33 -induced Smad7 expression, Smad3 siRNA was used to silence the Smad3 gene in HSCs. In the absence of Smad3, the expression of Smad7 was significantly reduced in HSCs treated with or without exogenous TGF- $\beta 3$, therefore indicating that Smad3 may be critical in TGF- $\beta 3$-induced Smad7 expression.

Various transcription factors have been reported to contribute to the induction of Smad7 transcription. The Smad7 promoter includes an SBE, to which R-Smads or an $\mathrm{R}-\mathrm{Smad} / \mathrm{Smad} 4$ complex can bind to activate the Smad7 promoter $(18,29)$. However, for Smad7 transcription to be potently induced, the involvement of other transcription factors or cofactors, such as stimulating protein-1, activator protein 1, transcription factor E3, activating transcription factor 2, p300 and forkhead box H1, is required (30-33). Notably, more than one CRE site in the Smad7 promoter has been reported, some of which lie at a close proximity to the SBE site, thereby suggesting that CREB1 and Smad 3 may both bind to the Smad7 promoter (29). The present results suggested that SBE may be an important site for Smad7 promoter activation, and the CRE site is near the SBE. Therefore, it may be hypothesized that CREB1 could act as a co-factor during the TGF- $\beta 3$-activated Smad7 transcription by binding with Smad3.

In conclusion, the present study demonstrated that TGF- $\beta 3$ induced Smad7 expression in HSCs, and CREB1 and Smad3 are implicated in the mechanism of induction, $\mathrm{Smad} 3$ is the key regulator while CREB-1 acts as a co-regulator. Furthermore, it may be hypothesized that CREB1 can cooperate with Smad3 to mediate a maximal induction of Smad7 transcription following stimulation by TGF- $\beta 3$. However, further experiments are required to investigate and validate this hypothesis.

\section{Acknowledgements}

The present study was funded by the National Natural Foundation of China (grant no. 3087 1153). The authors would like to thank the Institute of Liver Diseases of Shanghai University of Traditional Chinese Medicine for providing the HSCs cell line, and Dr Michael E. Greenberg (Department of Neurobiology, Harvard Medical School) for providing the pRSV-CREB-1 expression vector.

\section{References}

1. Wallace K, Burt AD and Wright MC: Liver fibrosis. Biochem J 411: 1-18, 2008.

2. Wells RG: Cellular sources of extracellular matrix in hepatic fibrosis. Clin Liver Dis 12: 759-768, viii, 2008.

3. Povero D, Busletta C, Novo E, di Bonzo LV, Cannito S Paternostro C and Parola M: Liver fibrosis: A dynamic and potentially reversible process. Histol Histopathol 25: 1075-1091, 2010.

4. Leask A and Abraham DJ: TGF-beta signaling and the fibrotic response. FASEB J 18: 816-827, 2004.

5. Li Q, Zhou X, Yu J, Qian W and Xu KS: Influence of recombinant transforming growth factor-beta3 on collagen synthesis and deposition: Experiment with rat cell model of liver fibrosis. Zhonghua Yi Xue Za Zhi 88: 1273-1278, 2008 (In Chinese).
6. Zhou X, Yu J, Li Q, Qian W and Xu KS: Effects of transforming growth factor-beta 3 gene transfer on type I collagen synthesis of hepatic stellate cells. Zhonghua Gan Zang Bing Za Zhi 16: 43-48, 2008 (In Chinese).

7. Zhang Y, Liu P, Gao X, Qian W and Xu K: rAAV2-TGF- $\beta(3)$ decreases collagen synthesis and deposition in the liver of experimental hepatic fibrosis rat. Dig Dis Sci 55: 2821-2830, 2010.

8. Massagué J: How cells read TGF-beta signals. Nat Rev Mol Cell Biol 1: 169-178, 2000.

9. Deng L, Li Y, Huang JM, Zhou Gy, Qian W and Xu K: Effects of p-CREB-1 on transforming growth factor-beta3 auto-regulation in hepatic stellate cells. J Cell Biochem 112: 1046-1054, 2011

10. Han S, Ritzenthaler JD, Rivera HN and Roman J: Peroxisome proliferator-activated receptor-gamma ligands suppress fibronectin gene expression in human lung carcinoma cells: Involvement of both CRE and Sp1. Am J Physiol Lung Cell Mol Physiol 289: L419-L428, 2005.

11. Chan EC, Dusting GJ, Guo N, Peshavariya HM, Taylor CJ, Dilley R, Narumiya S and Jiang F: Prostacyclin receptor suppresses cardiac fibrosis: Role of CREB phosphorylation. J Mol Cell Cardiol 49: 176-185, 2010.

12. Barlow CA, Barrett TF, Shukla A, Mossman BT and Lounsbury KM: Asbestos-mediated CREB phosphorylation is regulated by protein kinase A and extracellular signal-regulated kinases 1/2. Am J Physiol Lung Cell Mol Physiol 292: L1361-L1369, 2007.

13. Ionescu AM, Drissi H, Schwarz EM, Kato M, Puzas JE, McCance DJ, Rosier RN, Zuscik MJ and O'Keefe RJ: CREB Cooperates with BMP-stimulated Smad signaling to enhance transcription of the Smad6 promoter. J Cell Physiol 198: 428-440, 2004.

14. Livak KJ and Schmittgen TD: Analysis of relative gene expression data using real-time quantitative PCR and the 2(-Delta Delta C(T)) method. Methods 25: 402-408, 2001.

15. Shaywitz AJ and Greenberg ME: CREB: A stimulus-induced transcription factor activated by a diverse array of extracellular signals. Annu Rev Biochem 68: 821-861, 1999.

16. Nishihara H, Hwang M, Kizaka-Kondoh S, Eckmann L and Insel PA: Cyclic AMP promotes cAMP-responsive element-binding protein-dependent induction of cellular inhibitor of apoptosis protein-2 and suppresses apoptosis of colon cancer cells through ERK1/2 and p38 MAPK. J Biol Chem 279: 26176-26183, 2004.

17. Gustin JA, Pincheira R, Mayo LD, Ozes ON, Kessler KM, Baerwald MR, Korgaonkar CK and Donner DB: Tumor necrosis factor activates CRE-binding protein through a p38 MAPK/MSK1 signaling pathway in endothelial cells. Am J Physiol Cell Physiol 286: C547-C555, 2004.

18. Nagarajan RP, Zhang J, Li W and Chen Y: Regulation of Smad7 promoter by direct association with Smad3 and Smad4. J Biol Chem 274: 33412-33418, 1999.

19. Yan X, Liu Z and Chen Y: Regulation of TGF-beta signaling by Smad7. Acta Biochim Biophys Sin (Shanghai) 41: 263-272, 2009.

20. Nakao A, Afrakhte M, Morén A, Nakayama T, Christian JL, Heuchel R, Itoh S, Kawabata M, Heldin NE, Heldin CH and ten Dijke P: Identification of Smad7, a TGFbeta-inducible antagonist of TGF-beta signalling. Nature 389: 631-635, 1997.

21. Takase M, Imamura T, Sampath TK, Takeda K, Ichijo H, Miyazono K and Kawabata M: Induction of Smad6 mRNA by bone morphogenetic proteins. Biochem Biophys Res Commun 244: 26-29, 1998.

22. Hayashi H, Abdollah S, Qiu Y, Cai J, Xu YY, Grinnell BW, Richardson MA, Topper JN, Gimbrone MA Jr, Wrana JL and Falb D: The MAD-related protein Smad7 associates with the TGFbeta receptor and functions as an antagonist of TGFbeta signaling. Cell 89: 1165-1173, 1997.

23. Itoh S and ten Dijke P: Negative regulation of TGF-beta receptor/Smad signal transduction. Curr Opin Cell Biol 19: 176-184, 2007.

24. Zhang S, Fei T, Zhang L, Zhang R, Chen F, Ning Y, Han Y, Feng XH, Meng A and Chen YG: Smad7 antagonizes transforming growth factor beta signaling in the nucleus by interfering with functional Smad-DNA complex formation. Mol Cell Biol 27: 4488-4499, 2007.

25. Flanders KC: Smad 3 as a mediator of the fibrotic response. Int J Exp Pathol 85: 47-64, 2004.

26. Wang W, Koka V and Lan HY: Transforming growth factor-beta and Smad signalling in kidney diseases. Nephrology (Carlton) 10: 48-56, 2005. 
27. Lan HY: Smad7 as a therapeutic agent for chronic kidney diseases. Front Biosci 13: 4984-4992, 2008.

28. Liu G, Ding W, Neiman J and Mulder KM: Requirement of Smad3 and CREB-1 in mediating transforming growth factor-beta (TGF beta) induction of TGF beta 3 secretion. J Biol Chem 281: 29479-29490, 2006.

29. Stopa M, Anhuf D, Terstegen L, Gatsios P, Gressner AM and Dooley S: Participation of Smad2, Smad3 and Smad4 in transforming growth factor beta (TGF-beta)-induced activation of Smad7. The TGF-beta response element of the promoter requires functional Smad binding element and E-box sequences for transcriptional regulation. J Biol Chem 275: 29308-29317, 2000.

30. Brodin G, Ahgren A, ten Dijke P, Heldin CH and Heuchel R Efficient TGF-beta induction of the Smad7 gene requires cooperation between AP-1, Sp1, and Smad proteins on the mouse Smad7 promoter. J Biol Chem 275: 29023-29030, 2000.
31. Hua X, Miller ZA, Benchabane H, Wrana JL and Lodish HF: Synergism between transcription factors TFE3 and Smad3 in transforming growth factor-beta-induced transcription of the Smad7 gene. J Biol Chem 275: 33205-33208, 2000.

32. Uchida K, Suzuki H, Ohashi T, Nitta K, Yumura W and Nihei H: Involvement of MAP kinase cascades in Smad7 transcriptional regulation. Biochem Biophys Res Commun 289: 376-381, 2001.

33. Gohla G, Krieglstein K and Spittau B: Tieg3/Klf11 induces apoptosis in OLI-neu cells and enhances the TGF-beta signaling pathway by transcriptional repression of Smad7. J Cell Biochem 104: 850-861, 2008. 